\title{
Oxidative leaching of chromium from layered double hydroxides: Mechanistic studies
}

\author{
A V RADHA and P VISHNU KAMATH* \\ Department of Chemistry, Central College, Bangalore University, Bangalore 560 001, India
}

MS received 4 March 2004; revised 1 May 2004

\begin{abstract}
The layered double hydroxide (LDH) of $\mathrm{Zn}$ with $\mathrm{Cr}$ on treatment with a hypochlorite solution releases chromate ions as a result of oxidative leaching by a dissolution-reprecipitation mechanism. The residue is found to be $\varepsilon-\mathrm{Zn}(\mathrm{OH})_{2}$. The $\mathrm{LDH}$ of $\mathrm{Mg}$ with $\mathrm{Cr}$ on the other hand is resistant to oxidative leaching. In contrast, a X-ray amorphous gel of the coprecipitated hydroxides of $\mathrm{Mg}$ and $\mathrm{Cr}$ yields chromate ions. These results suggest that the oxidation potential of $\mathrm{Cr}$ (III) in LDHs is determined by the nature of the divalent ion and the crystallinity of the phase while being unaffected by the nature of the intercalated anions.
\end{abstract}

Keywords. Layered double hydroxide; stichtite; oxidative leaching; dissolution-reprecipitation.

\section{Introduction}

Anionic clays based on mineral stichtite, $\mathrm{Mg}_{6} \mathrm{Cr}_{2}(\mathrm{OH})_{16}$ $\left(\mathrm{CO}_{3}\right) \cdot 4 \mathrm{H}_{2} \mathrm{O}$, comprise positively charged layers having the composition $\left[\mathrm{M}(\mathrm{II})_{1-x} \mathrm{Cr}_{x}(\mathrm{OH})_{2}\right]^{x+}$ (Taylor 1973). Anions such as $\mathrm{CO}_{3}^{2-}$ are intercalated between the layers for the restoration of charge neutrality. A host of divalent ions such as Mg, Ni (Kooli et al 1995), Co (del Arco et al 1996), $\mathrm{Cu}$ (Grosso et al 1992) and Zn (Boehm et al 1977) can take the place of $\mathrm{M}$ (II) to yield a large number of compounds, which are more generally referred to as 'layered double hydroxides', (LDHs) (Cavani et al 1991). While other LDHs exhibit considerable compositional flexibility $(0 \cdot 2 \leq x \leq 0 \cdot 33)$ (Miyata 1980), the LDH of $\mathrm{Zn}$ with $\mathrm{Cr}^{3+}$ has a unique composition corresponding to $x=$ $0 \cdot 33$ (Boclair and Braterman 1998). This leads to the formula, $\mathrm{Zn}_{2} \mathrm{Cr}(\mathrm{OH})_{6}\left(\mathrm{CO}_{3}\right)_{1 / 2} \cdot y \mathrm{H}_{2} \mathrm{O}(y=2 \cdot 0)$. We abbreviate the formula of these LDHs as $\mathrm{M}-\mathrm{Cr}-\mathrm{A}(\mathrm{M}=\mathrm{Mg}, \mathrm{Zn}$; $\mathrm{A}=\mathrm{NO}_{3}^{-}, \mathrm{CO}_{3}^{2-}, \mathrm{Cl}^{-}$).

We have for some time been working on the use of Nibased LDHs as candidate electrode materials for alkaline secondary batteries (Kamath et al 1994). The LDH of $\mathrm{Ni}^{2+}$ with $\mathrm{Cr}^{3+}$ was shown to deliver a higher discharge capacity as compared to nickel hydroxide (Jayashree and Kamath 2002), but capacity fading was observed on cycling due to the oxidative leaching of $\mathrm{Cr}^{3+}$ in the form of the soluble $\mathrm{CrO}_{4}^{2-}$ ion. This observation got us interested in the mechanism of $\mathrm{Cr}^{3+}$ oxidation in LDHs. To examine this we employed the LDHs of $\mathrm{Cr}^{3+}$ with divalent ions such as $\mathrm{Mg}$ and $\mathrm{Zn}$, which, in contrast with $\mathrm{Ni}$, do not have any redox chemistry of their own.

\footnotetext{
*Author for correspondence
}

The motivation for the present investigation was (i) to determine the mechanism of oxidative leaching of $\mathrm{Cr}$ from the LDH lattice and (ii) to characterize the residue obtained at the end of the reaction.

\section{Experimental}

\subsection{Preparation of $\mathrm{LDHs}$}

The $\mathrm{Zn}-\mathrm{Cr}-\mathrm{A}\left(\mathrm{A}=\mathrm{NO}_{3}^{-}, \mathrm{Cl}^{-}\right) \mathrm{LDH}$ was prepared by the method of Boehm et al (1977). $2.5 \mathrm{~g}$ of $\mathrm{ZnO}$ was first suspended in $10 \mathrm{ml}$ of water. To this suspension, $10 \mathrm{ml}$ of $1 \mathrm{M} \mathrm{CrA}_{3}$ solution was added drop wise and stirred for a day. The $\mathrm{Cr}$ salt solution was fully decolourized and was replaced with a fresh aliquot. The suspension was then stirred for 6 days, after which the LDH was filtered, washed with copious quantities of water and dried at $65^{\circ} \mathrm{C}$. The $\mathrm{Zn}-\mathrm{Cr}-\mathrm{CO}_{3}^{2-} \mathrm{LDH}$ was prepared by ion exchange, by suspending a pre-weighed batch of the $\mathrm{Zn}-\mathrm{Cr}-\mathrm{NO}_{3}^{-}$ LDH in $100 \mathrm{ml}$ of an aqueous $\mathrm{Na}_{2} \mathrm{CO}_{3}$ solution containing three times the stoichiometric requirement of $\mathrm{CO}_{3}^{2-}$ ions for $24 \mathrm{~h}$. The suspension was then filtered, washed with water and dried at $65^{\circ} \mathrm{C}$.

The $\mathrm{Mg}-\mathrm{Cr}-\mathrm{CO}_{3}^{2-} \mathrm{LDH}$ was prepared by the method of coprecipitation (Kooli et al 1995). A mixed metal $\left(\mathrm{Mg}^{2+}+\mathrm{Cr}^{3+}\right)$ nitrate solution containing the required quantity of the metals in $3: 1$ ratio (total strength, $0.6 \mathrm{M}$ ) was added drop wise to a solution of $\mathrm{NaOH}+\mathrm{Na}_{2} \mathrm{CO}_{3}$ containing the stoichiometric requirement of $\mathrm{OH}^{-}$ions and a three-fold excess of $\mathrm{CO}_{3}^{2-}$ ions using a Metrohm Model 718 STAT titrino operated in the DOS mode at the rate of $3 \mathrm{ml} \mathrm{min}$. The resulting slurry was filtered, washed free of excess alkali and carbonate ions and dried at $65^{\circ} \mathrm{C}$. This as-prepared material was found to be X-ray amor- 
phous. To obtain a well crystallized LDH, the slurry obtained in a separate experiment was hydrothermally treated in a teflon lined autoclave $\left(75 \%\right.$ filling, $\left.180^{\circ} \mathrm{C}, 72 \mathrm{~h}\right)$ under autogenous pressure. The solid was then filtered, washed and dried to constant weight at $65^{\circ} \mathrm{C}$.

\subsection{Cr leaching experiments}

Oxidative leaching of $\mathrm{Cr}$ was carried out by suspending a pre-weighed $(500 \mathrm{mg}$ ) amount of the $\mathrm{LDH}$ in $50 \mathrm{ml}$ of $5 \%$ sodium hypochlorite (Nice Reagents, India) solution ( $\mathrm{pH}>$ 12) for $26 \mathrm{~h}$ under constant stirring. The residue was then filtered through a previously weighed sintered glass crucible, washed and dried at room temperature over $\mathrm{P}_{2} \mathrm{O}_{5}$. The percentage weight loss could thus be determined. The filtrate had the yellow colour of dissolved $\mathrm{CrO}_{4}^{2-}$ ions. The amount of $\mathrm{CrO}_{4}^{2-}$ in the leachate was determined gravimetrically as $\mathrm{BaCrO}_{4}$ using the standard procedure (Vogel 1978).

\subsection{Wet chemical analysis}

The residues obtained from the leaching experiments were subjected to chemical analysis. A preweighed amount of the residue was dissolved in a known amount of excess dilute $\mathrm{HCl}$. The hydroxyl content was estimated by back titrating the excess acid against standard $\mathrm{NaOH}$ pH metrically. The metal content was estimated by EDTA titrations. The unaccounted weight was attributed to water to arrive at an approximate formula, which was then found to be consistent with results of thermal analysis.

\subsection{Characterization}

All the samples were characterized by PXRD (Jeol Model JDX8P powder X-ray diffractometer, Co K $\alpha$ source, $\lambda=$
$1.79 \AA$ or Siemens D5005 diffractometer, $\mathrm{Cu} \mathrm{K \alpha}$ source, $\lambda=1.541 \AA$ ), infrared spectroscopy (Nicolet Model Impact 400D FTIR spectrometer, $4000-400 \mathrm{~cm}^{-1}, \mathrm{KBr}$ pellets, resolution, $4 \mathrm{~cm}^{-1}$ ) and thermogravimetry (lab. built system, heating rate, $5^{\circ} \mathrm{C} \min ^{-1}$ ).

\section{Results and discussion}

$\mathrm{Mg}(\mathrm{OH})_{2}$ crystallizes in a layered structure (space group $P-3 m 1 ; a=3.148 \AA$ and $c=4.772 \AA$ ) comprising a hexagonal close packing of hydroxyl ions, with $\mathrm{Mg}^{2+}$ occupying alternate layers of octahedral sites (Oswald and Asper 1977). When a fraction, $x$, of the $\mathrm{Mg}^{2+}$ ions are substituted by $\mathrm{Cr}^{3+}$, the layers acquire a composition, $\left[\mathrm{Mg}_{1-x} \mathrm{Cr}_{x}(\mathrm{OH})_{2}\right]^{x+}$ with a positive charge, to neutralize which, carbonates/ nitrates are intercalated in the interlayer region. This causes an increase in the interlayer spacing from $4.77 \AA$ seen in $\mathrm{Mg}(\mathrm{OH})_{2}$ (bivalent hydroxides) to a higher value, $7 \cdot 6 \AA$, seen in the LDHs. In figures $1 \mathrm{a}$ and $2 \mathrm{a}$ are shown the PXRD patterns of the LDHs of $\mathrm{Cr}^{3+}$ with $\mathrm{Zn}$ and $\mathrm{Mg}$, respectively. Both the LDHs exhibit a low angle $(2 \theta=$ $\left.10-14^{\circ}\right)$ reflection corresponding to their enlarged basal spacing. This is $8.86 \AA$ in the case of the $\mathrm{Zn}-\mathrm{Cr}-\mathrm{NO}_{3}^{-}$ $\mathrm{LDH}$ characteristic of the intercalated nitrate and is $7.73 \AA$ in the case of the $\mathrm{Mg}-\mathrm{Cr}-\mathrm{CO}_{3}^{2-} \mathrm{LDH}$ characteristic of the intercalated $\mathrm{CO}_{3}^{2-}$ ion (Miyata 1983). In figure $3 \mathrm{a}$ is given an illustrative IR spectrum of the $\mathrm{Zn}-\mathrm{Cr}-\mathrm{NO}_{3}^{-}$ $\mathrm{LDH}$. Strong vibrations due to the intercalated $\mathrm{NO}_{3}^{-}$ion can be seen at $1350-1380 \mathrm{~cm}^{-1}\left(v_{3}\right)$.

The oxidative leaching of $\mathrm{Cr}$ from the LDHs can take place by two possible mechanisms:

(I) The oxidation of $\mathrm{Cr}^{3+}$ to $\mathrm{Cr}(\mathrm{VI})$ followed by the topotactic removal of $\mathrm{Cr}(\mathrm{VI})$ from the lattice. $\mathrm{Cr}(\mathrm{VI})$ has a very small ionic radius $(0.26 \AA$ in 4-coordination and $0.44 \AA$ in 6-coordination) (Shannon 1976) and can in principle

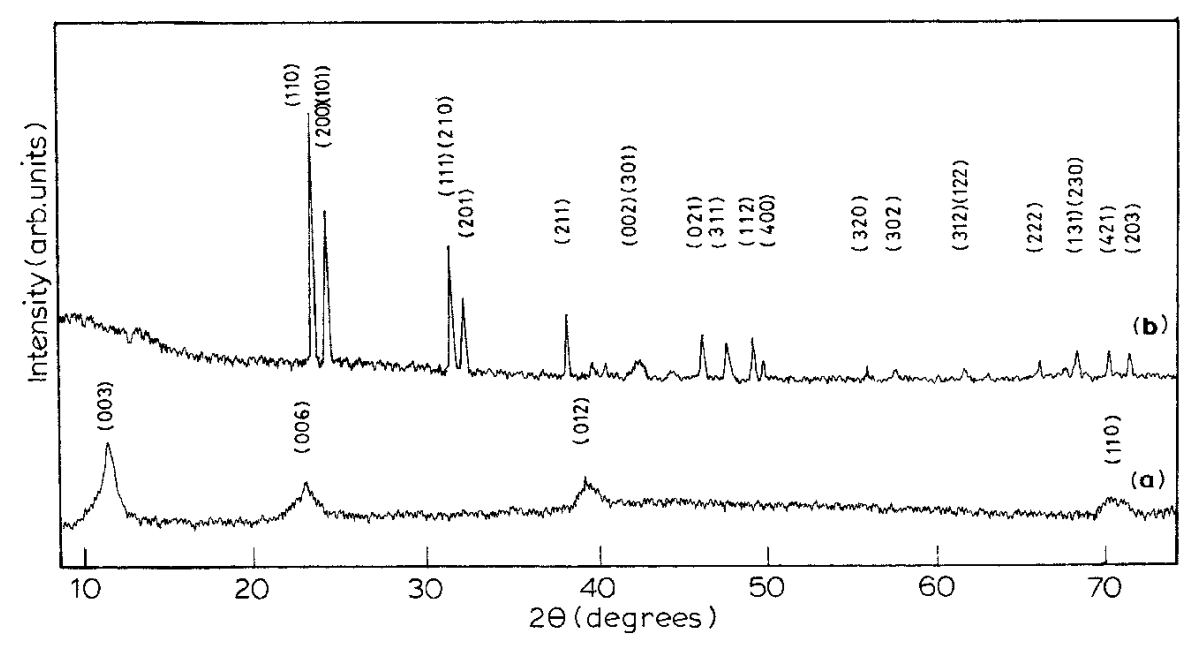

Figure 1. Powder X-ray diffraction patterns of $\mathrm{Zn}-\mathrm{Cr}-\mathrm{NO}_{3} \mathrm{LDH}$ (a) before and (b) after Cr leaching. 
diffuse through the triangular face of the $\left[\mathrm{M}(\mathrm{OH})_{6}\right]$ octahedron of the LDH layer, by a process known as diadochy. The $\mathrm{Cr}(\mathrm{VI})$ can then be hydrolyzed to the $\mathrm{CrO}_{4}^{2-}$ ion in the solution outside the LDH lattice. Cation exchange of divalent ions in LDHs has been shown to occur by this mechanism despite their much larger size (Komarneni et al 1998).

(II) The direct removal of $\mathrm{Cr}^{3+}$ as the $\mathrm{CrO}_{4}^{2-}$ ion by the disruption of the hydroxide layer, with $\mathrm{Cr}(\mathrm{VI})$ drawing away the oxygen of the lattice. The LDH would effectively dissolve and the bivalent hydroxide would then re- precipitate as an unary hydroxide. We refer to this as the dissolution-reprecipitation (D-R) mechanism.

If the former mechanism were to prevail, the end product of the reaction would also be a layered phase with a structure related to the original $\mathrm{LDH}$. The loss of $\mathrm{Cr}^{3+}$ would result in the elimination of the positive charge on the layer. Consequently there should be an equivalent reduction in the negative charge. Release of the intercalated carbonate/nitrate ions would yield a hydrated unary hydroxide of the formula, $\mathrm{M}(\mathrm{OH})_{2} \cdot y \mathrm{H}_{2} \mathrm{O}(y=0 \cdot 66-1 \cdot 0)$.

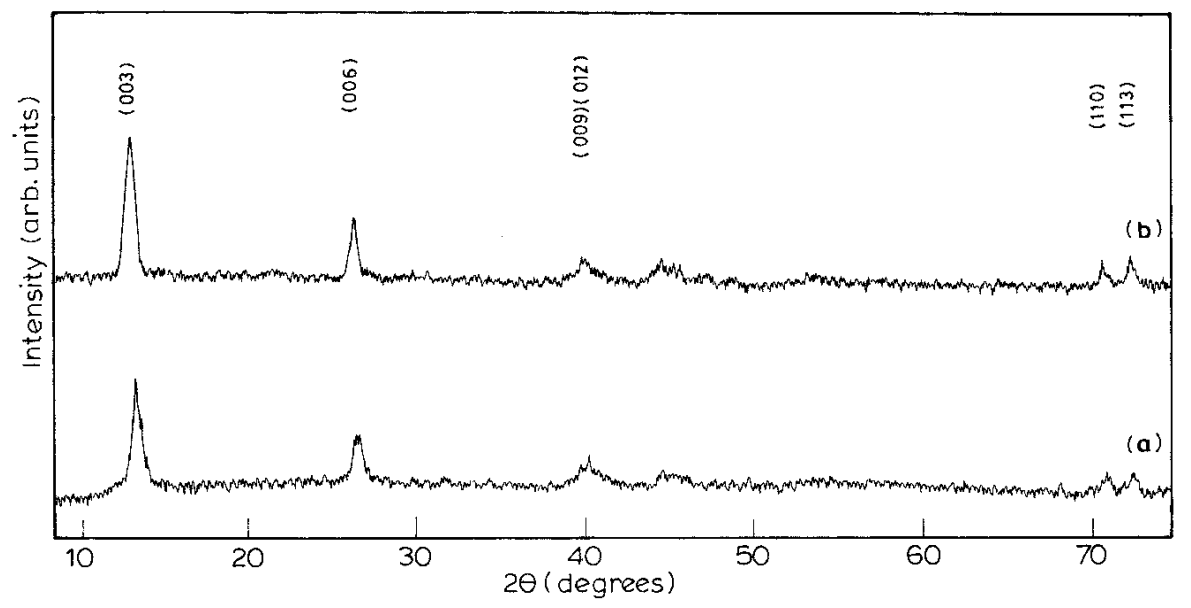

Figure 2. Powder $\mathrm{X}$-ray diffraction patterns of $\mathrm{Mg}-\mathrm{Cr}-\mathrm{CO}_{3} \mathrm{LDH}$ (a) before and (b) after Cr leaching.

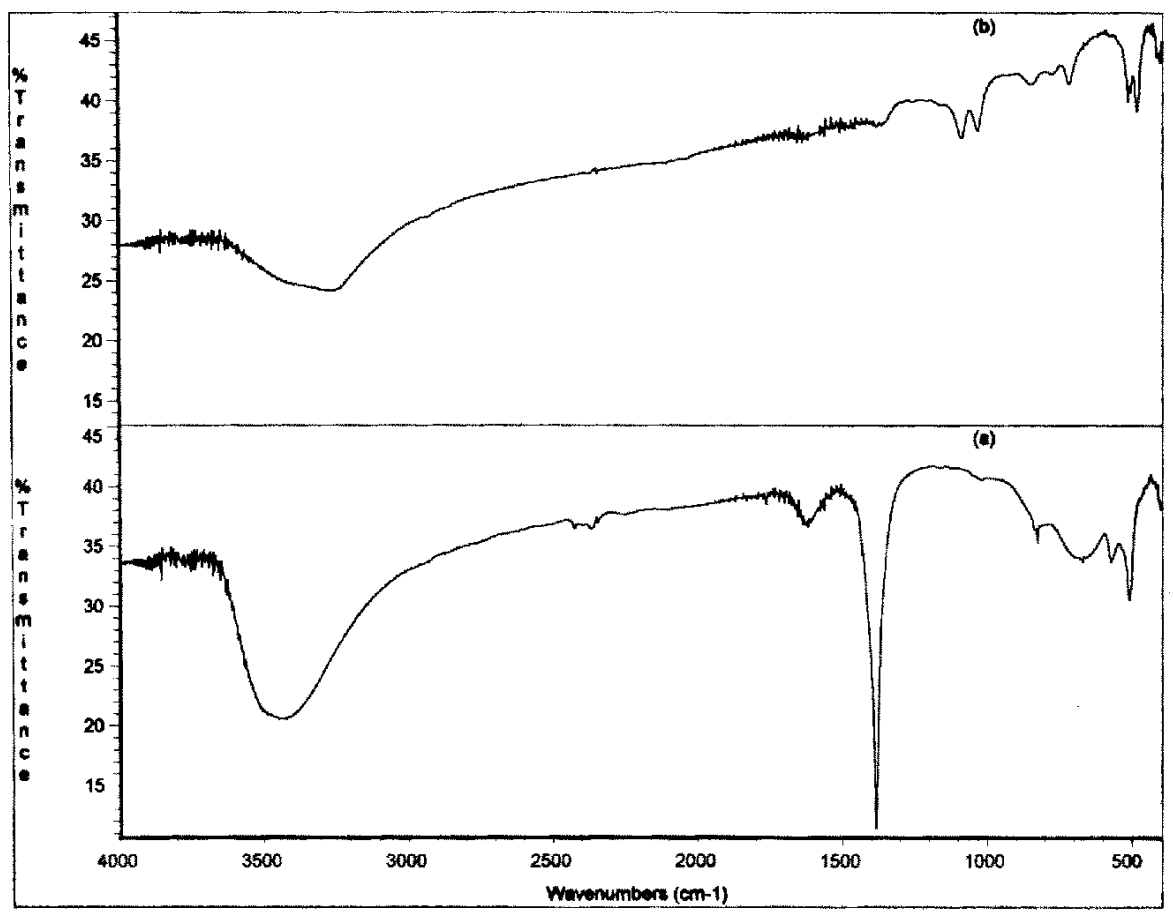

Figure 3. IR spectra of the $\mathrm{Zn}-\mathrm{Cr}-\mathrm{NO}_{3} \mathrm{LDH}$ (a) before and (b) after $\mathrm{Cr}$ leaching. 
Table 1. Results of the oxidative leaching of Cr in different LDH systems.

\begin{tabular}{lccc}
\hline & & \multicolumn{2}{c}{ Amount of Cr leached out (wt.\%) } \\
\cline { 3 - 4 } LDH system & $\begin{array}{c}\text { Weight loss after } \\
\text { Cr leaching (wt.\%) }\end{array}$ & Observed & Expected* \\
\hline $\mathrm{Zn}-\mathrm{Cr}-\mathrm{NO}_{3}$ & $48 \cdot 11$ & 14.53 & $13 \cdot 6$ \\
$\mathrm{Zn}-\mathrm{Cr}-\mathrm{CO}_{3}$ & 43.56 & 15.02 & $(13.4)$ \\
$\mathrm{Zn}-\mathrm{Cr}-\mathrm{Cl}$ & 44.0 & $15 \cdot 24$ & $14 \cdot 6$ \\
$\mathrm{Mg}-\mathrm{Cr}-\mathrm{CO}_{3}$ & $11 \cdot 04$ & 8 & $15 \cdot 9 * *$ \\
$\mathrm{Mg}-\mathrm{Cr}-\mathrm{CO}_{3}$ slurry & 35.63 & 8.71 & $-* * *$ \\
\hline
\end{tabular}

* Calculated for the formula, $\mathrm{Zn}_{2} \mathrm{Cr}(\mathrm{OH})_{6}\left(\mathrm{~A}^{n-}\right)_{x / n} \cdot 2 \mathrm{H}_{2} \mathrm{O}$ (value in parentheses calculated for four molecules of water); **calculated for the formula, $\operatorname{Mg}_{6} \mathrm{Cr}_{2}(\mathrm{OH})_{16}\left(\mathrm{CO}_{3}\right) \cdot 4 \mathrm{H}_{2} \mathrm{O}$; ***composition unknown.

Such hydroxides are known as $\alpha$-hydroxides (Oliva et al 1982). Release of hydroxyl ions on the other hand would yield phases of the composition, $\mathrm{M}(\mathrm{OH})_{2-x}\left(\mathrm{~A}^{n-}\right)_{x / n}$ (Gallezot and Prettre 1969). These are better known as hydroxysalts or basic salts. While both these types of phases have been shown to have a topotactic relationship with the LDHs (Kamath et al 1997; Rajamathi et al 2001), $\alpha$ hydroxides of $\mathrm{Mg}$ and $\mathrm{Zn}$ have not been stabilized and characterized with certainty.

If the D-R mechanism is valid, the product is expected to be the thermodynamically most stable modification. In the case of the $\mathrm{Mg}-\mathrm{Cr} \mathrm{LDH}$, the $\mathrm{D}-\mathrm{R}$ mechanism is expected to yield brucite-like $\mathrm{Mg}(\mathrm{OH})_{2}$ as the latter is not known to exhibit any polymorphism or interlayer chemistry. Among the various polymorphic modifications of $\mathrm{Zn}(\mathrm{OH})_{2}$, the stable form is $\varepsilon-\mathrm{Zn}(\mathrm{OH})_{2}$, which resembles the 3-dimensional structure of cristobalite with $\mathrm{Zn}^{2+}$ in tetrahedral coordination (Oswald and Asper 1977).

The results of the oxidative leaching of $\mathrm{Cr}$ are summarized in table 1. It is seen that in the case of the $\mathrm{Zn}-\mathrm{Cr}$ LDHs, $\mathrm{Cr}$ leaching is quantitative, whereas, $\mathrm{Mg}-\mathrm{Cr} \mathrm{LDH}$ does not yield any $\mathrm{Cr}$. In figure $3 \mathrm{~b}$ is shown the infrared spectrum of the residue obtained from the $\mathrm{Zn}-\mathrm{Cr}$ system. The strong absorptions due to the intercalated nitrates are absent, indicating that the intercalated nitrate ions have been eliminated from the lattice together with the removal of $\mathrm{Cr}$. In the $\mathrm{Mg}-\mathrm{Cr}$ system however, the anion related vibrations are retained (data not shown).

The question now arises as to the nature of residues. In the case of the $\mathrm{Mg}-\mathrm{Cr} \mathrm{LDH}$, the residue retains the $\mathrm{LDH}$ structure as is to be expected (see figure $2 b$ ) from the results of the $\mathrm{Cr}$ leaching experiments. In the case of the $\mathrm{Zn}-\mathrm{Cr}$ $\mathrm{LDH}$, the residue exhibits a PXRD pattern (see figure $1 \mathrm{~b}$ ) that can be assigned to $\varepsilon-\mathrm{Zn}(\mathrm{OH})_{2}$ (PDF: $\left.38-0385\right)$. The $\varepsilon-\mathrm{Zn}(\mathrm{OH})_{2}$ has been further characterized by wet chemical analysis (table 2) and TG studies (figure 4). Wet chemical analysis shows a ratio of $\mathrm{Zn} / \mathrm{OH}=0.5$ and an approximate formula, $\mathrm{Zn}(\mathrm{OH})_{2} \cdot 0 \cdot 22 \mathrm{H}_{2} \mathrm{O}$ and thermogravimetry exhibits a total weight loss of $22.0 \%$ (expected $21.3 \%$ ) corresponding to the decomposition

$$
\mathrm{Zn}(\mathrm{OH})_{2} \cdot 0 \cdot 22 \mathrm{H}_{2} \mathrm{O} \rightarrow \mathrm{ZnO}+1 \cdot 22 \mathrm{H}_{2} \mathrm{O} .
$$

Table 2. Results of wet chemical analysis of $\varepsilon-\mathrm{Zn}(\mathrm{OH})_{2}$ sample.

\begin{tabular}{lccc}
\hline $\begin{array}{l}\mathrm{Zn}^{2+} \\
(\text { wt.\% })\end{array}$ & $\begin{array}{c}\mathrm{OH}^{-} \\
(\text {wt.\%) }\end{array}$ & $\begin{array}{c}\mathrm{H}_{2} \mathrm{O} \\
(\text { wt.\%) }\end{array}$ & Approximate formula \\
\hline 62.89 & 32.78 & 4.59 & $\mathrm{Zn}(\mathrm{OH})_{2} \cdot 0 \cdot 22 \mathrm{H}_{2} \mathrm{O}$ \\
\hline
\end{tabular}

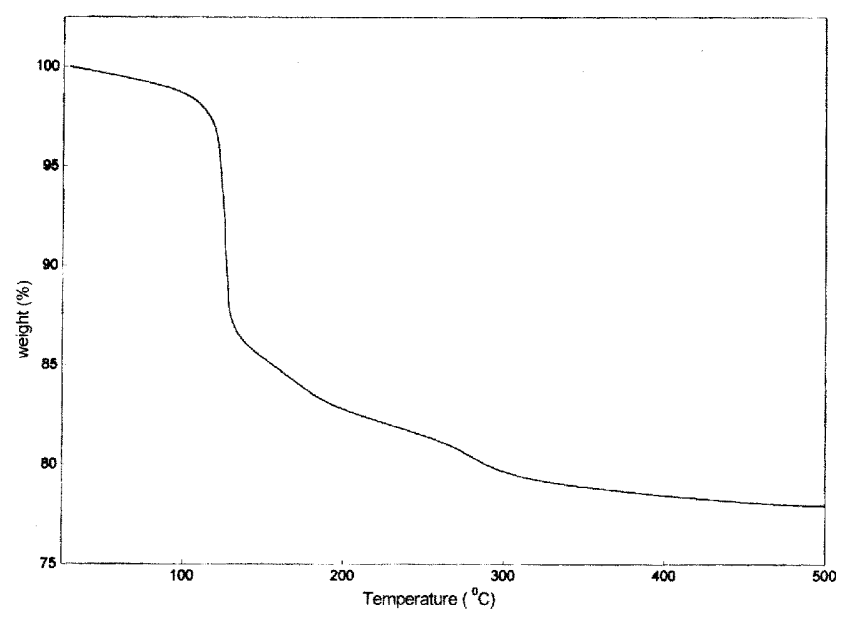

Figure 4. Thermogravimetric data of the residue obtained after $\mathrm{Cr}$ leaching from $\mathrm{Zn}-\mathrm{Cr}-\mathrm{NO}_{3}$.

In figure 5 we compare the structure of the $\mathrm{Zn}-\mathrm{Cr} \mathrm{LDH}$ with that of $\varepsilon-\mathrm{Zn}(\mathrm{OH})_{2}$. While $\mathrm{Zn}$ occupies octahedral sites in the former, the latter contains $\mathrm{Zn}$ in the tetrahedral sites. Clearly the transformation involving as it does a change in the coordination number of $\mathrm{Zn}$ proceeds via the D-R mechanism.

To see if the difference in reactivity between the two LDHs is merely due to the greater bulk solubility of the $\mathrm{Zn}-\mathrm{Cr} \mathrm{LDH}$ compared to the $\mathrm{Mg}-\mathrm{Cr} \mathrm{LDH}$, they were suspended in a $\mathrm{NaOH}$ solution $(\mathrm{pH}>12)$ having the same $\mathrm{pH}$ as that of the oxidant. The $\mathrm{Zn}-\mathrm{Cr}-\mathrm{NO}_{3} \mathrm{LDH}$ exhibited a final weight loss of $8.2 \%$. The following observations were made: (i) there was no trace of dissolved $\mathrm{Zn}^{2+}$ or $\mathrm{Cr}^{3+}$ in the liquid phase, even after $26 \mathrm{~h}$ of soaking; (ii) the residue obtained after $26 \mathrm{~h}$ of soaking retained the LDH structure (see figure 6) with an interlayer spacing of 


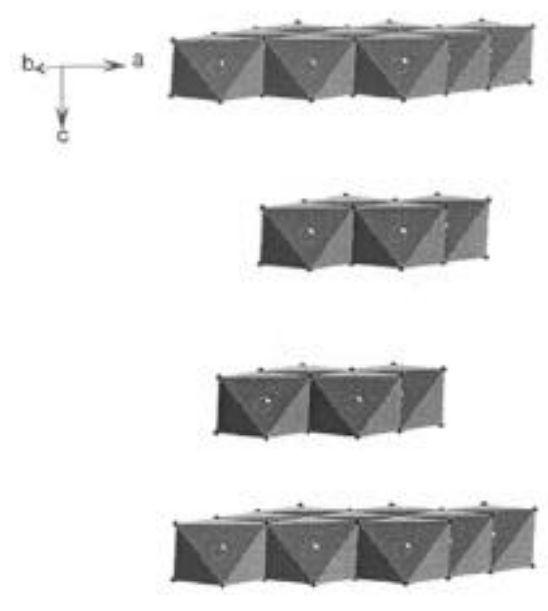

(a)

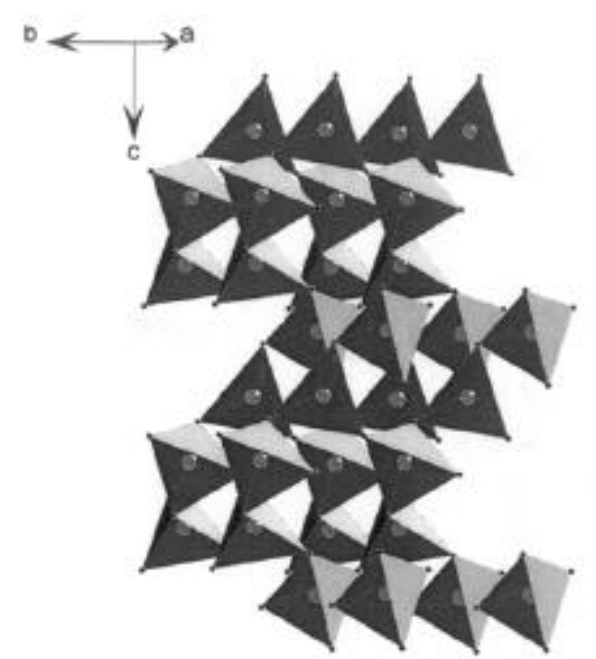

(b)

Figure 5. Structures of (a) $\mathrm{Zn}-\mathrm{Cr} \mathrm{LDH}$ (interlayer anions are not shown for clarity) and (b) $\varepsilon-\mathrm{Zn}(\mathrm{OH})_{2}$ viewed along the $b$-direction.

$7.73 \AA$ characteristic of the intercalated carbonate ions and (iii) the IR spectrum of the residue (data not shown) indicated the absence of $\mathrm{NO}_{3}^{-}$ions and the incorporation of $\mathrm{CO}_{3}^{2-}$ ions $\left(1367 \mathrm{~cm}^{-1}\right.$ and $\left.1393 \mathrm{~cm}^{-1}\right)$.

On the basis of these observations, we conclude that the observed weight loss is not due to the bulk dissolution of the $\mathrm{LDH}$, but due to the exchange of intercalated nitrates for carbonates present in the alkaline liquid phase according to the equation

$$
\begin{aligned}
& 2 \mathrm{Zn}_{2} \mathrm{Cr}(\mathrm{OH})_{6}\left(\mathrm{NO}_{3}\right) \cdot 2 \mathrm{H}_{2} \mathrm{O} \rightarrow \\
& \quad \mathrm{Zn}_{4} \mathrm{Cr}_{2}(\mathrm{OH})_{12}\left(\mathrm{CO}_{3}\right) \cdot 4 \mathrm{H}_{2} \mathrm{O}
\end{aligned}
$$

(Calculated mass change: $8 \cdot 36 \%$; observed: $8 \cdot 2 \%$ ).

The $\mathrm{Mg}-\mathrm{Cr}-\mathrm{CO}_{3}^{2-} \mathrm{LDH}$ exhibits a weight loss of $<1 \%$. As this LDH already contains carbonate ions, there is no avenue for further anion exchange. Unfortunately solubility products of $\mathrm{Cr}$ based LDHs have not been reported to date. The $\mathrm{Mg}-\mathrm{Cr}$ slurry exhibits a weight loss of $3.81 \%$ for unspecified reasons.

These results indicate that both LDHs have no significant bulk solubility. $\mathrm{Cr}$ leaching from $\mathrm{Zn}-\mathrm{Cr} \mathrm{LDH}$ is therefore not a trivial case of bulk dissolution of LDH followed by the oxidation of the free $\mathrm{Cr}^{3+}$ species to $\mathrm{CrO}_{4}^{2-}$. On the other hand this is genuine solid-solid transformation, dissolution-reprecipitation being a microscopic phenomenon that occurs only at the solid-liquid interface. Indeed our results indicate that the dissolution of the $\mathrm{Zn}-$ $\mathrm{Cr} \mathrm{LDH}$ at the microscopic level is driven by the $\mathrm{Cr}^{3+}$ oxidation reaction and not vice-versa.

The $\mathrm{Cr}^{3+}$ oxidation potential therefore appears to be different in the two LDHs. Several factors can in principle affect the oxidation potential of $\mathrm{Cr}$. Besides the nature of the divalent ion, other factors to be considered are (i)

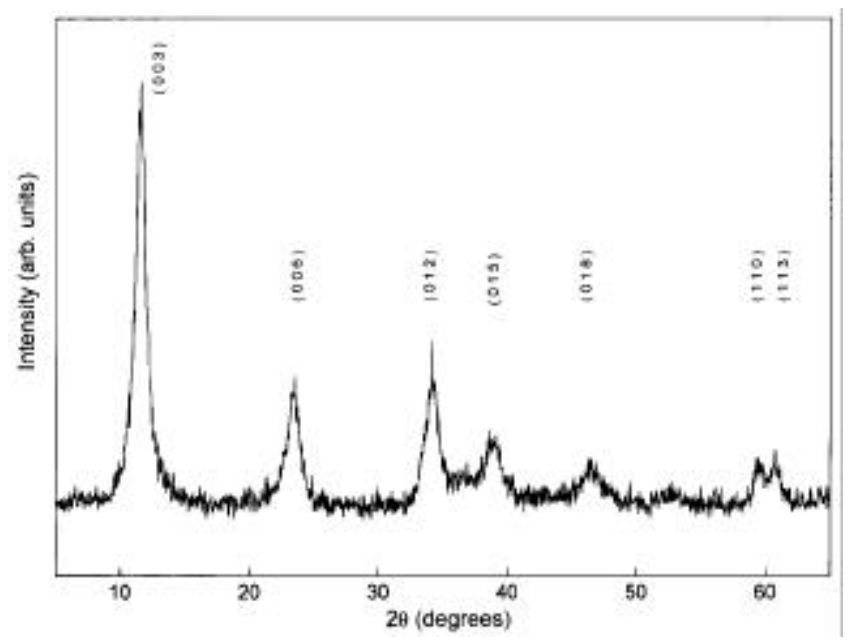

Figure 6. Powder $\mathrm{X}$-ray diffraction patterns of $\mathrm{Zn}-\mathrm{Cr}-\mathrm{NO}_{3}$ $\mathrm{LDH}$ aged in $\mathrm{NaOH}$ at $\mathrm{pH} 12$ (Source, $\mathrm{Cu} \mathrm{K} \alpha$ radiation).

nature of the intercalated anion and (ii) the crystallinity of the solid.

To examine these factors, $\mathrm{Cr}$ leaching was carried out from the $\mathrm{Zn}-\mathrm{Cr}-\mathrm{A}\left(\mathrm{A}=\mathrm{CO}_{3}^{2-}, \mathrm{Cl}^{-}\right) \mathrm{LDHs}$ as well. The fact that the $\mathrm{Zn}-\mathrm{Cr} \mathrm{LDH}$ yields $\mathrm{Cr}$ for all the three anions studied (table 1) suggests that the effect of the anion is not significant. To investigate the effect of crystallinity, $\mathrm{Cr}$ leaching experiments were carried out on the as precipitated X-ray amorphous gel of the $\mathrm{Mg}-\mathrm{Cr} \mathrm{LDH}$ as a control experiment to the well crystallized hydrothermally treated $\mathrm{Mg}-\mathrm{Cr} \mathrm{LDH}$. In contrast to that of the well crystallized $\mathrm{LDH}$, the gel yielded $\mathrm{Cr}$, showing that a long range ordering of the $\mathrm{LDH}$ lattice critically determines the reactivity of the solid. 


\section{Acknowledgements}

(PVK) thanks the Department of Science and Technology, New Delhi, for financial support. (AVR) thanks the University Grants Commission, New Delhi, for the award of a Senior Research Fellowship (NET). Authors thank the Solid State and Structural Chemistry Unit, Indian Institute of Science, Bangalore, for powder X-ray diffraction facilities. Authors thank the reviewer for his/her comments.

\section{References}

Boclair J W and Braterman P S 1998 Chem. Mater. 102050 Boehm H P, Steinle J and Vieweger C 1977 Angew. Chem. Int. Ed. Engl. 16265

Cavani F, Trifiro F and Vaccari A 1991 Catalysis Today 11 173

del Arco M, Galiano M V G, Rives V, Trujillano R and Malet P 1996 Inorg. Chem. 356362

Gallezot P and Prettre M 1969 Bull. Chim. Soc. (France) 407

Grosso R P, Suib S L, Weber R S and Schubert P F 1992 Chem. Mater. 4922
Jayashree R S and Kamath P V 2002 J. Power Sources 107120

Kamath P V, Dixit M, Indira L, Shukla A K, Kumar V G and Munichandraiah N 1994 J. Electrochem. Soc. 1412956

Kamath P V, Therese G H A and Gopalakrishnan J 1997 J. Solid State Chem. 12838

Komarneni S, Kozai N and Roy R 1998 J. Mater. Chem. 81329

Kooli F, Rives V and Ulibarri M A 1995 Inorg. Chem. 345122

Miyata S 1980 Clays Clay Minerals 2850

Miyata S 1983 Clays Clay Minerals 31305

Oliva P, Leonardi J, Laurent J F, Delmas C, Braconnier J J, Figlarz M, Fievet F and de Guibert A 1982 J. Power Sources 8229

Oswald H R and Asper R 1977 Preparation and crystal growth of materials with layered structures (ed.) R M A Lieth (Dordrecht: D. Reidel Publishing Company) 1 p. 71

Rajamathi M, Thomas G S and Kamath P V 2001 Proc. Indian Acad. Sci. (Chem. Sci.) 113671

Shannon R D 1976 Acta Crystallogr. A32 751

Taylor H F W 1973 Miner. Mag. 39377

Vogel's Text book of quantitative inorganic analysis including elementary instrumental analysis 1978 (eds) J Bassett, R C Denney, G H Jeffery and J Mendham (London: The English Language Book Society and Longman) 4th ed. 